\title{
Emma Vermelha e o espectro do "Tráfico de Mulheres"*
}

\section{Thaddeus Blanchette}

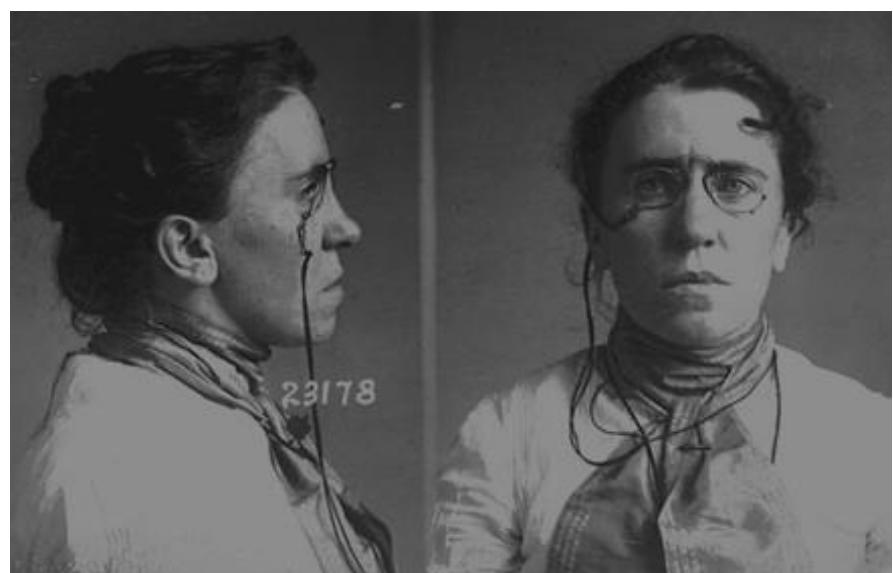

Figura 1: Foto de Emma Goldman, 1901,

aparentemente numa das várias ocasiões em que ela ficou presa. ${ }^{1}$

"O Tráfico de Mulheres" é provavelmente a primeira versão em língua portuguesa de um dos ensaios mais interessantes da mulher que certamente é a figura mais emblemática do anarquismo norte-americano: Emma Goldman. Pouco conhecida no Brasil, Goldman é uma das iconoclastas políticas mais duradouras do século passado. Suas críticas vivas tanto do nacionalismo e do capitalismo, quanto das utopias propostas por reformadores e revolucionários, parecem ganhar em relevância

\footnotetext{
* Recebido para publicação em 15 de agosto de 2011, aceito em 16 de setembro de 2011.

** Professor de Antropologia, UFRJ, Macaé. macunaima30@yahoo.com.br

1 Retirada de http://fuckyeahanarchopunk.tumblr.com/post/1352601629/ emmagoldman-1901-if-i-cant-dance-its-not-my
}

cadernos pagu (37), julho-dezembro de 2011: 287-297. 
enquanto nos afastamos do século que Hobsbawm (1994) chama de "A Era dos Extremos". Esse é particularmente o caso de "O Tráfico de Mulheres" que, embora escrito em 1910, continua a apresentar uma crítica relevante para a questão do "tráfico de pessoas" nas primeiras décadas do século XXI.

A continuada importância do pensamento de Goldman é fruto de sua visão pouco ortodoxa das lutas políticas e culturais de seu tempo. Enquanto muitos de seus contemporâneos acreditavam em modelos ideológicos que pregavam o autoritarismo em nome da construção de uma sociedade ideal, "Emma Vermelha" duvidava de qualquer filosofia que louvasse a repressão. Embora fosse uma anarquista que não desprezava a violência como ferramenta revolucionária (aos 23 anos planejava com seu amante, Alexander Berkman, o assassinato do magnata Henry Clay Frick), Goldman nunca endeusou qualquer ideologia a ponto de perder de vista as políticas cotidianas que Foucault, mais tarde, rotularia de controle e disciplina. Não só se preocupava com a luta de classes e as políticas de massa, como também enxergava as inúmeras maneiras com que o poder invade a vida cotidiana, condicionando mentes, corpos e almas.

$\mathrm{O}$ pensamento social de Emma parece prefigurar aquilo que hoje chamamos de interseccionalidade, buscando sempre perceber "as relações entre as múltiplas dimensões e modalidades de relações sociais na formação dos sujeitos" (McCall, 2005). Central no pensamento de Goldman é uma crítica aguda de gênero e de suas interações com outras categorias de ordenação social, particularmente classe, moralidade e sexualidade. Esta última categoria não era residual para ela, mas constituía um dos princípios da vida: Emma acreditava que a emancipação sexual tinha que estar entre os objetivos principais de qualquer movimento revolucionário.

Embora Goldman provavelmente nunca tenha enunciado a frase famosa, atribuída a ela pelos jovens anarquistas da minha geração - "Se não posso dançar, não quero fazer parte de sua revolução" (Shulman, 1991) - a importância que ela dava à política 
da vida cotidiana transparece na seguinte seleção de sua autobiografia:

Nas danças, fui sempre a mais incansável e feliz. Uma noite, um jovem primo de Sasha [Alexander Berkman] me puxou para uma conversa. Com rosto sério, como se fosse anunciar a morte de um camarada bem amado, me sussurrou que não era apropriado a um militante dançar. Certamente não com tanto vigor incauto, pelo menos. Não era digno de uma pessoa que estava subindo no movimento anarquista. Minha leviandade só poderia machucar A Causa.

Fiquei furiosa com a interferência impudente do menino. Eu o avisei para não se meter na minha vida. Eu tinha me cansado de ter A Causa jogada no meu rosto. Eu não acreditava que uma Causa que pregava um ideal bonito, o anarquismo, $e$ a nossa liberação das convenções $e$ preconceitos deveria insistir na negação da vida e da alegria. Eu insistia que a nossa Causa não poderia esperar que eu me transformasse em freira e que o movimento não podia ser uma clausura. Se era isto que a Causa significava, eu não a queria. "Eu quero a liberdade, o direito de autoexpressão, o direito de todos às coisas bonitas $e$ radiantes". O anarquismo significava isto, para mim, e eu viveria assim apesar de todo o mundo - prisões, perseguição e tudo o mais. Sim, mesmo apesar da condenação de meus próprios camaradas, eu viveria meu ideal bonito (Goldman, 1934).

Tal visão do mundo e da liberdade fez de Emma Goldman inimiga jurada de comunistas e capitalistas, sendo expulsa dos EUA na primeira grande onda de xenofobia anti-imigrantista $e$ anti-socialista em 1919 e, dois anos mais tarde, sendo declarada persona non grata na União Soviética.

As expressões políticas de Emma para com as questões feministas de sua época, de que "O Tráfico de Mulheres" é talvez o mais conhecido (e certamente o mais topical), estavam 
intimamente interligadas com suas experiências como mulher, imigrante e operária.

Nascida em 1869, em uma família pobre em Kovno, no Império Russo, Emma experimentaria as formas típicas da violência de gênero direcionadas às mulheres de sua época. Seu pai frequentemente a chicoteava por desobediência, fato que Goldman mais tarde julgaria ser fruto da frustração sexual dele (Chalberg, 1991:13; Goldman, 1934:cap. 34). Quando menina, sua mãe a espancava por masturbação e por expressar sentimentos sensuais e ela também foi brutalizada e molestada por seus professores na escola primária. Mesmo assim era aluna assídua (Goldman, 1934:cap. 2; Drinnon, 1961:6-7). Aos 15 anos, porém, Goldman foi proibida por seu pai de continuar seus estudos. Jogando a gramática de sua filha na fogueira, Abraham Goldman declarou: "Meninas não precisam aprender muito! Uma filha judaica precisa saber é preparar peixe recheado, cortar massa fina e dar ao homem muitos filhos" (Goldman, 1934:cap. 1).

Mais ou menos na mesma época, Goldman teve sua primeira experiência de intercurso sexual, que ela qualificava como "violenta" e "dolorosa" (Chalberg entende a experiência como estupro). Após esse episódio, ela sempre se sentiu "entre duas fogueiras em relação aos homens. Embora a atração por eles continuasse forte, estava misturada com uma repulsa violenta" (Chalberg, 1991:16; Goldman, 1934:cap. 2).

Apesar de todas essas experiências negativas, após migrar para os EUA em 1884 e tornar-se membro do movimento anarquista americano, Goldman viraria uma fervorosa proponente da liberdade sexual. Sua biógrafa, Alice Wexler, cita a seguinte afirmação de Goldman, que parece expressar sua filosofia sobre sexo, amor e liberdade:

Insisto na independência da mulher, seu direito para se autossustentar; de viver para si; para amar quem quiser ou quantos quiser. Demando a liberdade para ambos os sexos, 
a liberdade de ação, a liberdade no amor e a liberdade em ser mãe [motherhood] (Wexler, 1984:94).

Tais sentimentos eram radicais para os Estados Unidos nas primeiras décadas do século XX. Caracteristicamente, porém, "Emma Vermelha" foi muito além da questão do voto para as mulheres em sua militância. Falava publicamente em favor do amor livre e do controle da natalidade, fatos que contribuíram para sua prisão, em 1916, por violar a lei federal que proibia a distribuição de informações sobre contracepção e aborto (id.ib.:211-215).

Goldman entendia a liberdade sexual como uma questão mais abrangente do que a grande maioria das feministas de sua época. Como outras radicais, ela denunciava o casamento como "um arranjo econômico" que condenava a mulher "à dependência, ao parasitismo, à inutilidade completa, tanto individual quanto social" (Goldman, 1911c.). Todavia, ela iria mais longe do que a maioria dos proponentes do amor livre em seu tempo, pois Emma também foi uma das primeiras figuras públicas estadunidenses a apoiar a homossexualidade. Da mesma maneira, Goldman foi uma das poucas mulheres de seu tempo - senão a única - que falava em prol da liberação feminina e que tentou se prostituir (embora sem sucesso).

A relação de Emma com o movimento feminista de sua época, como era de se esperar, foi conturbada. Apesar de ela ser hoje reconhecida como a fundadora do "anarcofeminismo", Goldman entendia as feministas de seu tempo - da assim chamada "primeira onda" do feminismo - como figuras trágicas, iludidas pela promessa de uma igualdade construída sob as condições do capitalismo liberal.

Goldman achava a preocupação feminina com o direito de voto uma espécie de "fetiche" ou "superstição", pois entendia a democracia americana como uma farsa, um jogo político cínico que ocultava as coordenadas verdadeiras, econômicas, do poder: 
O pobre, estúpido, livre cidadão americano! Livre para morrer de fome, livre para andar pelas estradas desse país grande; ele goza do voto e, com esse direito, ele tem forjado as correntes em torno de seus membros. A recompensa que ele recebe são leis de trabalho draconianas que proíbem o direito do boicote, do piquete, de tudo de fato, fora o direito de ser roubado dos frutos de seu trabalho (Goldman 1911a).

Embora apoiasse a liberação feminina, Goldman criticava duramente as mulheres de seu tempo por sua fé no Estado e na democracia, chegando a comentar amargamente que o sexo feminino, em sua maioria, aparentemente apoiava exatamente aquelas instituições que mais oprimiam as mulheres: a igreja, a guerra e o lar. Goldman afirmava que uma minoria das mulheres buscava o direito de voto para se livrar do controle dessas instituições, mas afirmava:

a maioria das suffragists [militantes em favor do voto para as mulheres] repudia absolutamente tal blasfêmia. Pelo contrário: elas afirmam sempre que é o voto que vai transformar a mulher numa cristã e dona de casa melhor, uma cidadã fiel do Estado (id.ib.).

Dessa maneira, Goldman entendia o movimento pelos direitos iguais para as mulheres como fatalmente envenenado pelo fato de que tais direitos, "dados" por um Estado capitalista fundado em preceitos morais e econômicos de desigualdade, jamais poderiam redundar na igualdade. E foi justamente aqui que ela percebeu um efeito nocivo da entrada das mulheres no campo formal da política: negada uma igualdade real, mas dado o poder formal de uma cidadania limitada por classe, comportamento sexual e raça, a mulher americana tendia a cair em cruzadas morais que resultavam na limitação das liberdades das mulheres entendidas como "impuras": 
Portanto, no [estado de] Idaho, [a mulher suffragette] tem retirado o voto de sua irmã das ruas e tem declarado todas as mulheres "de caráter dúbio" inaptas a votar. Tal "dubiedade de caráter" não sendo interpretada como prostituição, é claro, desde que aconteça DENTRO do casamento (id.ib.).

Na visão de Goldman, esse falso moralismo tendia a resultar em tentativas de "moralizar" as classes mais baixas através da proibição da prostituição e da jogatina. Todavia, tais leis não resultaram na eliminação desses males, mas em sua propagação dentro de um regime de clandestinidade: "a prostituição e o jogo nunca floresceram tanto, desde que a lei se virou contra eles" (id. ib.). Aqui, Goldman previa a falha de uma das grandes bandeiras sustentadas pela maior parte do movimento de mulheres das primeiras décadas do século XX nos EUA: a proibição das bebidas alcoólicas. $^{2}$

Em vez de depender das leis e do Estado para seus direitos, Goldman advogava a ideia de que as mulheres deveriam procurar tais ideais dentro de si para sua liberação, desafiando primeiro os moralismos internalizados, particularmente com respeito ao amor $e$ ao sexo, e usando esse desafio como base para transformações sociais libertárias:

Precisamos do crescimento desenfreado para sair dos velhos hábitos e tradições. $O$ movimento para a emancipação da mulher tem dado, até agora, só um passo preliminar nessa direção... [A] verdadeira emancipação não começa nem nas cabines de voto, nem no tribunal. Começa na alma da mulher... [A emancipação completa da mulher] há de descartar a noção absurda do dualismo dos sexos, ou de que o homem e a mulher representam dois mundos antagônicos (Goldman, 1911b).

2 Para mais informações sobre o desenvolvimento histórico do feminismo nesse período e suas interações com outras tendências políticas e culturais, ver Kraditor (1981). 
Embora Emma Goldman entendesse a liberdade feminina como componente-chave de uma revolução mais ampla, tal liberdade, por si só, não constituiria um elemento revolucionário se continuasse enclausurada no sistema moral e econômico do capitalismo. Sem ser acompanhado por uma política revolucionária da vida cotidiana que desafiava as moralidades sexuais vigentes, o movimento das mulheres era facilmente desviado para cruzadas moralistas.

É com base nestas ideias de Emma Goldman que o leitor deve se aproximar de "O Tráfico de Mulheres".

O texto foi escrito em 1910, momento de auge do primeiro grande pânico moral sobre o tráfico de mulheres nos EUA ${ }^{3}$, resultando na passagem do Ato Mann, que proibia o transporte interestadual de mulheres para "fins imorais". A nova lei mirava na repressão da prostituição e foi apoiada por uma série de agentes políticos, inclusive boa parte do movimento de mulheres. Em seu texto, Goldman criticava a nova legislação moralista contra o tráfico, tema que, para ela, só servia para divertir um público infantilizado e largamente apolítico e aumentar uma classe particular de servidores do Estado - rotulados por ela de "parasitas" - que seria encarregada da vigilância (inútil) da moralidade pública. Para Goldman, aquilo que fazia a prostituição florescer e crescer não eram as condições morais das mulheres que "caíam" na profissão, tampouco dos homens que alugam seus favores, mas as realidades econômicas da sobrevivência feminina sob condições do capitalismo.

Aqui, Goldman monta um argumento que parece ser opaco até hoje para muitos dos militantes do movimento anti-tráfico. Ela situa a prostituição como fruto da exploração, mas de uma exploração que vai muito além do campo sexual e que abrange quase todas as formas de trabalho disponíveis nos horizontes de possibilidades das mulheres de seu tempo. De acordo com

\footnotetext{
${ }^{3}$ Para uma visão mais ampla sobre o fenômeno do "tráfico de escravas brancas", ver Dozema (2000).
} 
Goldman, o capitalismo oferece para a mulher duas opções: trabalhar ou se vender. No segundo caso, a única questão é se vai se vender para um homem só (socialmente aceitável, desde que esteja dentro dos limites do casamento monogâmico), ou se vender para vários. Para Goldman, a diferença entre essas duas posições não é absoluta e sim de grau.

Para a mulher que não consegue ou não quer se vender resta uma só opção: o trabalho. Mas a mão de obra feminina, observa Goldman, é altamente desvalorizada em quase todas as suas atividades, sendo que a mulher nunca é "tratada de acordo com o mérito de seu trabalho, mas apenas como sexo"4. Isso faz com que o trabalho seja uma forma de exploração até mais onerosa, em muitos casos, que a venda do corpo. Não é de se surpreender que muitas mulheres se perguntem: "Por que desperdiçar sua vida trabalhando por alguns centavos por semana na lavagem de pratos e panelas, dezoito horas por dia?" 5 .

Nesse sentido, de acordo com Goldman, a prostituição não é uma condição decadente, fruto da amoralidade, e muito menos um caso de escravidão, situada em franco contraste com a "liberdade" do trabalho ou do casamento. A venda do sexo é o resultado natural de um sistema econômico que não compensa o trabalhador feminino com um salário capaz de competir com os ganhos da venda de sexo:

Em outras palavras, a empregada doméstica, sendo tratada como uma faz-tudo, nunca tendo direito sobre si mesma, e esgotada pelos caprichos de sua patroa, pode encontrar uma saída, assim como a garota vendedora de loja, ou a trabalhadora fabril, apenas na prostituição. ${ }^{6}$

\footnotetext{
${ }^{4}$ Citação da tradução publicada nesta edição.

${ }^{5}$ Idem.

${ }^{6}$ Idem.
} 
Nesse cenário, a prostituição feminina só poderia crescer, apesar de todas as leis e as cruzadas morais direcionadas contra ela.

Essa é a lição primordial que levo do ensaio de Emma Goldman sobre o tráfico de mulheres, embora exista muito mais a ser aproveitado do texto. Quando o sistema socioeconômico e político é baseado na exploração econômica sistemática dos mais fracos, a prostituição aparece como saída para muita gente: a assim chamada "exploração sexual" simplesmente não pode ser retratada como especial, destacada da exploração econômica em geral. Tentar reprimir a prostituição, sem simultaneamente criar um sistema socioeconômico mais justo, há de ter o efeito de piorar as condições das trabalhadoras do sexo e, paradoxalmente, aumentar as injustiças que os reformistas dizem querer eliminar. É desmoralizante, então, perceber que - após um século - ainda lutamos para fazer aparecer as coordenadas básicas do tráfico que Emma Goldman enxergava com tanta clareza em 1910.

\section{Referências bibliográficas}

Chalberg, John. Emma Goldman: American Individualist. New York, Harper Collins, 1991.

DOZEMA, Jo. Loose Women or Lost Women? The re-emergence of the myth of 'white slavery' in contemporary discourses of 'trafficking in women'. Gender Issues, vol. 18, n 1, Winter 2000, pp.23-50.

DRINNON, Richard. Rebel in Paradise: A Biography of Emma Goldman. Chicago, University of Chicago Press, 1961.

GolDMAN, Emma. Living my Life. 1934. Disponível no "Anarchy Archives" [http://dwardmac.pitzer.edu/anarchist_archives/goldman].

. Woman Suffrage. Anarchism and Other Essays. Second Revised Edition. New York \& London, Mother Earth Publishing Association, 1911a. Disponível no "Anarchy Archives". [http://dwardmac.pitzer.edu/anarchist_archives/goldman].

. The Tragedy of Woman's Emancipation. Anarchism and Other Essays. Second Revised Edition. New York \& London, Mother 
Earth Publishing Association. 1911b. Disponível no "Anarchy Archives".

. Marriage and Love. Anarchism and Other Essays. Second Revised Edition. New York \& London, Mother Earth Publishing Association. 1911c. Disponível no "Anarchy Archives". Http://dwardmac.pitzer.edu/anarchist archives/goldman

HoBSBAWM, Eric. Era dos Extremos, O breve século XX, 1914-1991. São Paulo, Companhia das Letras, 1994.

KRADITOR, A.S. The Ideas of the Woman's Suffrage Movement, 18901920. NYC, W.W. Norton \& Company, 1981.

MCCALL, Leslie. The complexity of intersectionality. Signs: Journal of Women in Culture and Society, vol. 30, $n^{\circ} 3$, Chicago, University of Chicago, 2005.

SHULman, Alix Kates. Dances with feminists. Women's Review of Books, vol. IX, n 3, December 1991.

WeXLER, Alice. Emma Goldman: An Intimate Life. New York, Pantheon, 1984 [http://dwardmac.pitzer.edu/anarchist_archives/goldman]. 